\title{
ANALISIS KELAYAKAN INVESTASI PERLUASAN PABRIK DENGAN METODE COST-VOLUME-PROFIT DAN INCREMENTAL PADA PT XYZ, JAKARTA
}

\author{
Jonny \\ Department of Industrial Engineering, Faculty of Engineering, Binus University \\ Jln. K.H. Syahdan No. 9 Palmerah Jakarta Barat 11480 \\ jonny@binus.ac.id
}

\begin{abstract}
PT XYZ received an offer of toll manufacturing services from its client as much as 360 units at a price of Rp14.000 for four years. To be able to fulfill the offer, the company must issue an investment of Rp1,3 billion for the plant expansion regarding to the limited capacity and specificity of the engine that must be purchased separately. There is also some additional operational cost for the company. Based on the analysis of costvolume-profit (CVP) the company realized that the price offered is far below the desired corporate profit by $27 \%$ so that the new price agreed upon in the negotiation is Rp16.000. Meanwhile, using the price agreement and macroeconomic assumption for the next four years, the company can finally concluded to accept the offer of its client with a value weighted NPV up to Rp306, 5 million based on the incremental analysis.
\end{abstract}

Keywords: investment, cost-volume-profit (CVP), incremental analysis

\begin{abstract}
ABSTRAK
PT XYZ menerima tawaran jasa maklon dari kliennya sebanyak 36.000 unit dengan harga Rp14.000 selama empat tahun. Untuk dapat memenuhi tawaran tersebut, perusahaan harus mengeluarkan investasi sebesar Rp1,3 Milyar untuk perluasan pabrik mengingat kapasitas yang terbatas dan kekhususan mesin yang harus dibeli terpisah. Selain itu, terdapat pula biaya operasional yang tentunya dapat menambah beban perusahaan. Berdasarkan analisis Cost-Volume-Profit (CVP) perusahaan menyadari bahwa harga yang ditawarkan jauh dibawah profit yang diinginkan perusahaan sebesar $27 \%$ sehingga dalam negosiasi disepakati harga baru sebesar Rp16.000. Sementara itu, dengan menggunakan harga kesepakatan dan asumsi makro ekonomi selama empat tahun kedepan, perusahaan akhirnya dapat menyimpulkan untuk menerima tawaran klien dengan nilai weighted NPV mencapai Rp306,5 juta berdasarkan analisis incremental.
\end{abstract}

Kata kunci: investasi, cost-volume-profit (CVP), analisis incremental 


\section{PENDAHULUAN}

PT XYZ merupakan perusahaan farmasi yang bergerak di bidang jasa Maklon sejak tahun 1996 dengan jumlah karyawan 95 orang. Adapun produk yang telah dihasilkan antara lain: obat hormon, obat tiroid, dan obat KB “Andalan” dengan lokasi pabrik yang berada di Bintaro, Jakarta Selatan dan Head Office di Menteng, Jakarta Pusat.

Saat ini, perusahaan mendapatkan tawaran bisnis dari klien berupa jasa toll manufacturing (maklon) baru. Namun demikian, karena terbatasnya kapasitas pabrik dan kekhususan produk yang harus dibuat, untuk dapat menerima penawaran bisnis ini, perusahaan harus melakukan investasi mesin dan perluasan bangunan. Selain itu, terdapat pula tambahan biaya rutin yang harus dikeluarkan untuk dapat memenuhi permintaan dari klien tersebut.

Seperti pada tawaran bisnis lainnya, pada tawaran bisnis inipun terdapat resiko yang harus ditanggung perusahaan apabila produk yang diproduksi tidak memenuhi standar yang telah ditetapkan. Resiko tersebut berupa denda yang harus ditanggung apabila kesepakatan yang tidak dapat dipenuhi nilainya lebih besar dari biaya jasanya karena sanksi harga per unit ini termasuk harga material dalam membuat produk ini.

Mengingat besarnya tambahan investasi yang harus dikeluarkan oleh perusahaan untuk dapat memenuhi permintaan klien, perusahaan ingin mengkaji tingkat profitabilitas dari tawaran bisnis yang diterima dari klien sebelum mengambil komitmen untuk mengambil tawaran tersebut. Dalam hal ini, pihak klien juga terbuka untuk melakukan negosiasi. Untuk itu ada beberapa hal yang harus dianalisis oleh perusahaan sebelum mengambil keputusan apakah akan menerima atau menolak tawaran bisnis yang diberikan oleh klien.

Adapun hal-hal yang dimaksud sebagai berikut: (1) Apakah tawaran yang diajukan klien sudah sesuai dengan tingkat profit yang diinginkan perusahaan sebesar minimal 27\% dari Net Sales? Jika belum, berapa tingkat harga yang harus dinegosiasikan ke pihak klien? Pertama, hal ini dilakukan dengan melakukan simulasi perhitungan tingkat profitabilitas per unit produk yang ditawarkan. Apabila net income yang diperoleh kurang dari 27\% seperti yang diinginkan oleh pemilik perusahaan, dilakukan analisis CVP (Cost-Volume-Profit) (Berk \& DeMarzo, 2007) di mana biaya operasional yang ada dikelompokkan menurut sifatnya apakah biaya tetap atau variabel. Setelah itu, dicari harga yang diinginkan agar perusahaan dapat meraih keuntungan sesuai yang diharapkan. Kemudian harga ini dinegosiasikan kepada pihak pemberi kerja. Apabila disetujui, langkah berikutnya dihitung berapa volume yang harus dikerjakan agar perusahaan tidak mengalami kerugian dengan menggunakan metode BEP (Berk \& DeMarzo, 2007). Apabila volume yang ditawarkan melebihi volume pada tingkat BEP, volume dinyatakan layak untuk diterima; (2) Jika negosiasi harga yang diajukan perusahaan disetujui, apakah tawaran ini tetap menarik mengingat beratnya sanksi yang dikenakan klien apabila perusahaan tidak dapat memenuhi spesifikasi klien? Pada bagian ini, dilakukan incremental analysis (Berk \& DeMarzo, 2007) dengan mempertimbangkan perubahan biaya apabila tawaran dari pemberi kerja diterima.

Selanjutnya dilakukan proyeksi free cash flow (Berk \& DeMarzo, 2007) untuk 4 tahun kedepan sesuai masa kontrak yang ditawarkan. Kemudian, dilakukan NPV analysis dengan expected return sebesar 14\% (industri farmasi) (Berk \& DeMarzo, 2007) dengan 2 skenario yaitu skenario 1 tidak ada batch yang ditolak dan skenario 2 maksimal 1 batch ditolak karena tidak terpenuhinya persyaratan yang telah ditetapkan. Dari kedua NPV yang dihasilkan selanjutnya dilakukan perhitungan weighted NPV sebesar $95.25 \%$ Skenario 1 dan $4.75 \%$ Skenario 2 berdasarkan risk premium industry farmasi. Apabila nilainya positif, tawaran layak diambil. 


\section{METODE}

Untuk dapat memecahkan permasalahan yang dihadapi perusahaan, ada dua analisis yang harus dilakukan dengan menggunakan metode Cost-Volume-Profit dan Incremental melalui NPV Analysis seperti yang ditunjukkan pada bagan berikut (Gambar 1).

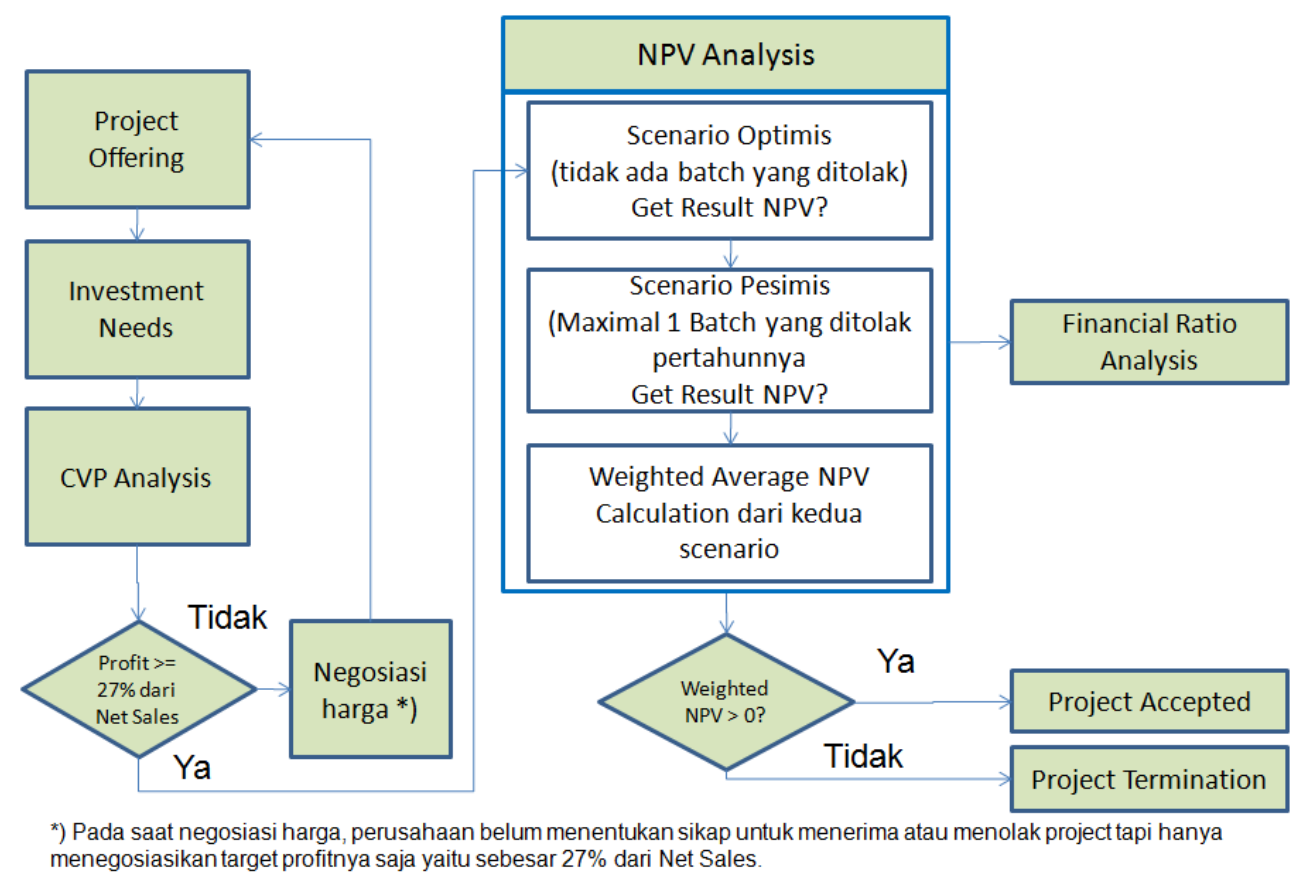

Gambar 1. Metodologi penelitian.

Gambar 1 menjelaskan mengenai metodologi penelitian yang dilakukan untuk menganalisis kelayakan investasi atas tawaran yang diterima. Untuk itu ada ada skenario yang diambil, yaitu skenario optimis di mana tidak ada batch yang ditolak dan skenario pesimis di mana maksimal 1 batch ditolak karena tidak sesuai permintaan. Masing-masing skenario akan menghasilkan NPV sehingga perlu dicari weighted NPV. Apabila hasilnya positif, proyek layak diterima. Namun apabila proyek tidak laya, sebaiknya ditolak.

\section{HASIL DAN PEMBAHASAN}

Data yang diperlukan untuk menganalisis kelayakan investasi adalah sebagai berikut: (1) nilai penawaran dari klien, yaitu dengan harga Rp14.000, volume sebanyak 36.000 unit, selama 4 tahun; (2) nilai investasi. Tabel 2 menunjukkan bahwa untuk dapat menerima proyek yang ditawarkan, perlu adanya penambahan mesin senilai Rp900 Juta dengan masa pakai 4 tahun dan nilai sisa Rp150 Juta dan perluasan pabrik dengan nilai Rp200 Juta dan umur pakai 20 tahun; (3) biaya operasional dilihat dari incremental analysis, seperti yang ditunjukkan pada Tabel 3; (4) besaran sanski, seperti yang ditunjukkan pada Tabel 4. 
Tabel 2

Nilai Investasi

\begin{tabular}{|l|r|r|r|}
\hline Rincian & Nilai Awal & Nilai Sisa & Umur Pakai (th) \\
\hline Investasi & & & 4 \\
\hline -Mesin & $900,000,000$ & $150,000,000.00$ & 20 \\
\hline -Factory Expansion & $200,000,000$ & & \\
\hline
\end{tabular}

Tabel 3

Biaya Operasional

\begin{tabular}{|l|r|l|}
\hline \multicolumn{1}{|c|}{ Rincian } & \multicolumn{1}{|c|}{ Jumlah } & \multicolumn{1}{|c|}{ Keterangan } \\
\hline Biaya Training & $45,000,000$ & $\begin{array}{l}\text { Untuk6 orang selama 5 hari @ Rp } \\
1.500 .000,00 \text { per orang per hari }\end{array}$ \\
\hline Biaya Utilities & $42,000,000$ & $\begin{array}{l}\text { Tambahan biaya Rp 3.500.000,00 per } \\
\text { bulan }\end{array}$ \\
\hline $\begin{array}{l}\text { Alokasi Biaya Tenaga Kerja \& } \\
\text { Overhead }\end{array}$ & $71,250,000$ & $\begin{array}{l}\text { Biaya- biaya yang terkait dengan } \\
\text { penanganan dan produksi untuk project } \\
\text { klien }\end{array}$ \\
\hline $\begin{array}{l}\text { Alokasi Biaya Selling \& General } \\
\text { Admin }\end{array}$ & $3,750,000$ & \\
\hline
\end{tabular}

Tabel 4

Sanksi

\begin{tabular}{|l|r|}
\hline 1 batch (unit) & 1,000 \\
\hline Harga per unit (Rp) & 175,000 \\
\hline Loss perbatch (Rp) & $175,000,000$ \\
\hline
\end{tabular}

Tabel 4 di atas menunjukkan bahwa apabila perusahaan tidak berhasil memenuhi persyaratan produk yang telah ditetapkan, perusahaan harus menunggung sangsi. Apabila dalam 1 batch gagal melalui proses QC, batch tersebut harus ditolak sehingga perusahaan harus menanggung kerugiaan Rp175 Juta (termasuk biaya material) sementara pendapatan jasa maklon hanya mencapai Rp14 Juta.

Untuk dapat mengetahui apakah tawaran klien sesuai dengan tingkat profit yang diinginkan perusahaan, analisis profitabilitas per unit perlu dilakukan dan hasilnya ditunjukkan pada Tabel 5 berikut:

Tabel 5

Profitabilitas

\begin{tabular}{|c|c|c|c|c|c|}
\hline \multirow{2}{*}{\multicolumn{6}{|c|}{$\frac{\text { Decription }}{\text { (Fixed \& Variable Cost) }}$}} \\
\hline & & & & & \\
\hline Sales Volume & 36,000 & & Sales Volume & & \\
\hline Selling Price & 14,000 & & Selling Price & & \\
\hline Total Sales & $504,000,000$ & 14000 & OTotal Sales & 14000 & $100.00 \%$ \\
\hline Direct Material & - & & OVariable Cost & 0 & $0.00 \%$ \\
\hline & & & Contribution Margin & 14000 & $100.00 \%$ \\
\hline Direct Labor \& Overhead & $71,250,000$ & 1979 & 9Direct Material & 0 & $0.00 \%$ \\
\hline Training & $45,000,000$ & 1250 & ODirect Labor \& Overhead & 1979 & $14.14 \%$ \\
\hline Utillities & $42,000,000$ & 1167 & Training & 1250 & $8.93 \%$ \\
\hline $\begin{array}{l}\text { Depreciation (Building \& } \\
\text { Machine) }\end{array}$ & $197,500,000$ & 5486 & GUtillities & 1167 & $8.33 \%$ \\
\hline & & & Depreciation (Building \& Machine) & 5486 & $39.19 \%$ \\
\hline & & & Selling Expense \& General Admin & 104 & $0.74 \%$ \\
\hline COGS plus Depreciation & $355,750,000$ & 9,882 & Fixed Cost & 9,986 & $71.33 \%$ \\
\hline Gross Profit & $148,250,000$ & 4118 & & +3 & \\
\hline Selling Expense \& General & & & & & \\
\hline Admin & $3,750,000$ & 104 & & & \\
\hline Operating Income & $144,500,000$ & 4,014 & Operating Income & 4,014 & $28.67 \%$ \\
\hline Other Income/ Expense & - & & dOther Income/ Expense & 0 & $0.00 \%$ \\
\hline EBT & $144,500,000$ & 4,014 & EBT & 4,014 & $28.67 \%$ \\
\hline $\operatorname{Tax}$ & $40,460,000$ & 1,124 & $\operatorname{Tax}$ & 1,124 & $8.05 \%$ \\
\hline Net Income & $104,040,000$ & 2,890 & Net Income & 2,890 & $20.64 \%$ \\
\hline
\end{tabular}


Dari tabel diatas, dapat kita ketahui bahwa dengan selling price Rp140 per unit, net income hanya mencapai Rp2.890 per unit atau 20.64\%. Karena persentase net income tersebut masih dibawah keinginan perusahaan yaitu 27\%, perlu dilakukan proses negosiasi melalui perhitungan CVP Analysis dengan hasil sebagai berikut (Tabel 6):

Tabel 6

CVP Analysis

\begin{tabular}{|l|r|}
\hline Volume & 36000 \\
\hline Sales & $36000 \mathrm{P}$ \\
\hline Variable Cost & $36000 \mathrm{P}$ \\
\hline Contribution Margin & $359,500,000$ \\
\hline Fixed Cost & $36000 \mathrm{P}-359,500,000$ \\
\hline Profit Before Tax & $27 \%^{*} 36000 \mathrm{P}$ \\
\hline Tax $(36000 \mathrm{P}-359,500,000)$ & $36000 \mathrm{P}-359,500,000$ \\
\hline Profit After Tax & $10,080 \mathrm{P}-100,660,000$ \\
\hline Profit Before Tax & $9720 \mathrm{P}$ \\
\hline Tax & $25,920 \mathrm{P}-258,840,000$ \\
\hline Profit After Tax & $10200 \mathrm{P}$ \\
\hline $9720 \mathrm{P}$ & 16,000 \\
\hline \multicolumn{1}{|c|}{$258,840,000$} & \\
\hline P & \\
\hline
\end{tabular}

\begin{tabular}{|l|r|}
\hline Sales & $576,000,000$ \\
\hline Variable Cost & $576,000,000$ \\
\hline Contribution Margin & $359,500,000$ \\
\hline Fixed Cost & $216,500,000$ \\
\hline Operating Income & \\
\hline & \\
\hline DOL & $(576,000,000 / 216,500,000)=2,66$ \\
\hline BEP (\%) & $(359,500,000 / 576,000,000)=60=00 /$ \\
\hline BEP (Units) & 22,469 \\
\hline BEP (Sales) & \\
\hline Margin of Safety & $1 / \mathrm{DOL}=1 / 2.66=0.376=216,500,000$ \\
\hline
\end{tabular}

Dari tabel di atas, dapat kita ketahui bahwa untuk dapat mencapai target profit 27\%, maka selling price harus ditetapkan sebesar Rp16.000 per unit. Untuk itu, pihak perusahaan mengajukan harga sebesar Rp16.000. Setelah negosiasi dilakukan, akhirnya klien bisa menerima pengajuan harga ini. Sementara itu, untuk mencapai BEP, perusahaan harus memproduksi setidaknya 22.469 unit dengan nilai DOL (Degree of Leverage) sebesar 2.66. Maka dari itu, setiap kenaikan 10\% dari Sales, Operating Income dari proyek ini akan naik 26.6\%. Dengan kesepakatan harga ini, permasalahan pertama dari perusahaan terpecahkan. Selanjutnya, untuk dapat menjawab permasalahan kedua, perlu dilakukan analisis Cash Flow perusahaan selama 4 tahun masa kontrak sebagaimana yang ditunjukan dalam Tabel 7 berikut:

Tabel 7

Cash Flow

\begin{tabular}{|c|c|c|c|c|c|}
\hline Decription & Total & Per Unit & Cash Flow & Per Unit & Per Unit \\
\hline & & & & 2009 & $2010-2012$ \\
\hline Sales Volume & 36,000 & & 36,000 & & \\
\hline Selling Price & 16,000 & & 16,000 & & \\
\hline Total Sales & $576,000,000$ & 16000 & $576,000,000$ & 16000 & 16000 \\
\hline Direct Material & & 0 & - & 0 & 0 \\
\hline Direct Labor \& Overhead & $71,250,000$ & 1979 & - & 0 & 0 \\
\hline Training & $45,000,000$ & 1250 & $45,000,000$ & 1,250 & 0 \\
\hline Utillities & $42,000,000$ & 1167 & $42,000,000$ & 1,167 & 1167 \\
\hline Depreciation (Building \& Machine) & $197,500,000$ & 5486 & $197,500,000$ & 5,486 & 5486 \\
\hline COGS plus Depreciation & $355,750,000$ & 9,882 & $284,500,000$ & 7,903 & 6,653 \\
\hline Gross Profit & 220.250 .000 & 6,118 & $291,500,000$ & 8,097 & 9,347 \\
\hline Selling Expense \& General Admin & $3,750,000$ & 104 & $3,750,000$ & 0 & 0 \\
\hline Operating Income & $216,500,000$ & 6,014 & $287,750,000$ & 8,097 & 9,347 \\
\hline Other Income/ Expense & - & 0 & - & 0 & 0 \\
\hline EBT & $216,500,000$ & 6,014 & $287,750,000$ & 8,097 & 9,347 \\
\hline Tax & $60,620,000$ & 1,684 & $80,570,000$ & 2,267 & 2,617 \\
\hline Net Income & $155,880,000$ & 4,330 & $207,180,000$ & 5,830 & 6,730 \\
\hline
\end{tabular}


Dari tabel diatas, dapat kita ketahui bahwa biaya training hanya dikenakan di tahun 2009, selanjutnya biaya training ini bisa dihilangkan. Sementara biaya direct labor \& overhead serta biaya selling expense and general admin tidak dimasukkan karena tidak mengalami perubahan. Ada tidaknya proyek ini, biaya tersebut tetap ada (sunk cost). Untuk itu, dalam perhitungan FCFE, biayabiaya ini tidak diperhitungkan karena biaya-biaya ini hanya sebagai alokasi biaya ke proyek baru untuk mengestimasi profitability dari proyek yang ditawarkan oleh klien.

Berikutnya diambil beberapa asumsi makro ekonomi selama kontrak berjalan dengan rincian sebagai berikut:

Kenaikan inflasi $\quad=10 \%$ di tahun 2010 ke atas

Expected Return $\quad=$ WACC industri farmasi (Tabel 8) $=14 \%$ (BI Rate $(9.25 \%)+$ Risk Premium

$(4.75 \%))$

Corporate Tax $2009=28 \%$

Umur Kontrak (umur analisis kelayakan) $=4$ tahun

Tabel 8

WACC

\begin{tabular}{|c|c|c|c|}
\hline & Pharmaceuticals & $\begin{array}{l}\text { Control } \\
\text { sample I }\end{array}$ & $\begin{array}{l}\text { Control } \\
\text { sample It }\end{array}$ \\
\hline \multicolumn{4}{|l|}{ Characteristics of industry } \\
\hline Market value of equity (s million) & $\$ 1,288$ & $\$ 453$ & $\$ 562$ \\
\hline Value of debe (S million) & 585 & $\$ 116$ & $\$ 120$ \\
\hline Averaoe firm value (S million) & 51,373 & $\$ 569$ & 569 \\
\hline \multicolumn{4}{|l|}{ Assumptions } \\
\hline Bees & 0.9 & 1.0 & 1.29 \\
\hline Cost of debt (pretax) & 0.09 & 0.09 & 0.09 \\
\hline Marginal tax rahe & 0.46 & 0.46 & 0.46 \\
\hline Risk free tase (x.) & 0.063 & 0.068 & 0.068 \\
\hline Market nisk premium $\left(r_{-}-t\right)$ & 0.087 & 0.087 & 0.007 \\
\hline \multicolumn{4}{|l|}{ Results } \\
\hline Cost of equity capital (r) & 0.146 & 0.155 & 0.18 \\
\hline Cost of captal (r) & 0.14 & 0.133 & 0.155 \\
\hline
\end{tabular}

Selanjutnya, dihitung pula biaya depresiasi yang terjadi selama masa kontrak sebagaimana yang ditunjukkan pada Tabel 9 berikut:

Tabel 9

Depreciation Cost

\begin{tabular}{|l|l|l|l|l|l|l|}
\hline \multicolumn{1}{|c|}{ Item } & Jumlah & Depr. Per year & Umur Pakai & Salvage Value & Depr.4 tahun & $\begin{array}{c}\text { Nilai Buku } \\
\text { Pd. Akhir } \\
\text { tahun ke 4 }\end{array}$ \\
\hline Factory Expansion & $200,000,000$ & $10,000,000$ & 20 & & $40,000,000$ & $160,000,000$ \\
\hline Machine and Installation & $900,000,000$ & $187,500,000$ & 4 & $150,000,000$ & $750,000,000$ & $150,000,000$ \\
\hline Total & & $197,500,000$ & & & & \\
\hline
\end{tabular}

Dari tabel diatas, dapat kita ketahui bahwa biaya depresiasi per tahun sebesar Rp197,5 juta. Dalam rangka memperhatikan prinsip risk adverse, dalam melakukan NPV analysis, digunakan dua skenario sebagai berikut:

Skenario 1: tidak ada batch yang ditolak. 
Skenario 2: maksimal 1 batch yang ditolak per tahunnya.

Berikut hasil NPV analysis berdasarkan skenario 1: tidak ada batch yang ditolak (Tabel 10).

Tabel 10

Skenario 1

\begin{tabular}{|c|c|c|c|c|c|c|}
\hline & 0 & 1 & 2 & 3 & 4 & \multirow{29}{*}{$\begin{array}{l}\text { Note: } \\
\text { 1. Efek inflasi } \\
\text { diperhitungkan }\end{array}$} \\
\hline & 2008 & 2009 & 2010 & 2011 & 2012 & \\
\hline Sales Volume & & 36,000 & 36,000 & 36,000 & 36,000 & \\
\hline Total Sales & & $576,000,000$ & $576,000,000$ & $576,000,000$ & $576,000,000$ & \\
\hline Direct Material & & - & - & - & - & \\
\hline Direct Labor \& Overhead & & - & - & - & - & \\
\hline Training & & $45,000,000$ & & - & - & \\
\hline Utillities & & $42,000,000$ & $46,200,000$ & $50,820,000$ & $55,902,000$ & \\
\hline Depreciation (Building \& Machine) & & $197,500,000$ & $197,500,000$ & $197,500,000$ & $197,500,000$ & \\
\hline COGS & & $284,500,000$ & $243,700,000$ & $248,320,000$ & $253,402,000$ & \\
\hline Gross Profit & & $291,500,000$ & $332,300,000$ & $327,680,000$ & $322,598,000$ & \\
\hline SGA & & - & - & - & - & \\
\hline Operating Income & & $291,500,000$ & $332,300,000$ & $327,680,000$ & $322,598,000$ & \\
\hline Other Income/Loss & & - & - & - & - & \\
\hline PBT & & $291,500,000$ & $332,300,000$ & $327,680,000$ & $322,598,000$ & \\
\hline $\operatorname{Tax}$ & & $81,620,000$ & $93,044,000$ & $91,750,400$ & $90,327,440$ & \\
\hline Net Income & & $209,880,000$ & $239,256,000$ & $235,929,600$ & $232,270,560$ & \\
\hline Depreciation & & $197,500,000$ & $197,500,000$ & $197,500,000$ & $197,500,000$ & \\
\hline Net Working Capital & 0 & & & & & \\
\hline \multicolumn{6}{|l|}{ Fixed Asset Investment } & \\
\hline Machine & $(900,000,000.00)$ & & & & & \\
\hline \begin{tabular}{|l|} 
Building \\
\end{tabular} & $(200,000,000.00)$ & & & & & \\
\hline \multicolumn{6}{|l|}{ Terminal Value } & \\
\hline -Machine & & & & & $150,000,000.00$ & \\
\hline Building & & & & & $160,000,000.00$ & \\
\hline FCFE & $(1,100,000,000)$ & $407,380,000$ & $436,756,000$ & $433,429,600$ & $739,770,560$ & \\
\hline Expected Return & $14 \%$ & & & & & \\
\hline Discounted Factors & 1.00 & 0.88 & 0.77 & 0.67 & 0.59 & \\
\hline PV & $(1,100,000,000,00)$ & \begin{tabular}{|l|l}
$357,350,877.19$ & \\
\end{tabular} & $336,069,559.86$ & $292,552,634.28$ & $438,003,558.36$ & \\
\hline
\end{tabular}

Dari tabel diatas, dapat kita ketahui bahwa untuk Shareholder Value Added skenario 1 di mana tidak ada satupun batch yang ditolak klien adalah Rp324 juta. Selanjutnya untuk skenario 2 adalah sebagai berikut (Tabel 11).

Dari tabel diatas, dapat kita ketahui bahwa untuk shareholder value added (SVA) skenario 2 dengan maximal satu batch yang ditolak klien per tahunnya adalah minus Rp43.2 juta. Untuk dapat mengambil keputusan apakah menerima tawaran klien atau tidak, nilai SVA dari kedua skenario dirata-ratakan berdasarkan bobot yang telah ditentukan sebagai berikut (Tabel 12):

Dari tabel diatas, dapat kita ketahui bahwa untuk Nilai Weighted NPV dari proyek ini adalah Rp306,5 juta. Ini menunjukkan bahwa walaupun ada kemungkinan satu batch produksi yang ditolak dan menyebabkan minus NPV Rp43,2 juta, proyek ini tetap menguntungkan pihak perusahaan karena resiko kejadian terjadinya penolakan batch sangat kecil yaitu $4.75 \%$ (risk premium untuk Industri farmasi). Hal ini menunjukkan layaknya tawaran ini untuk diterima oleh perusahaan. 
Tabel 11

Skenario 2

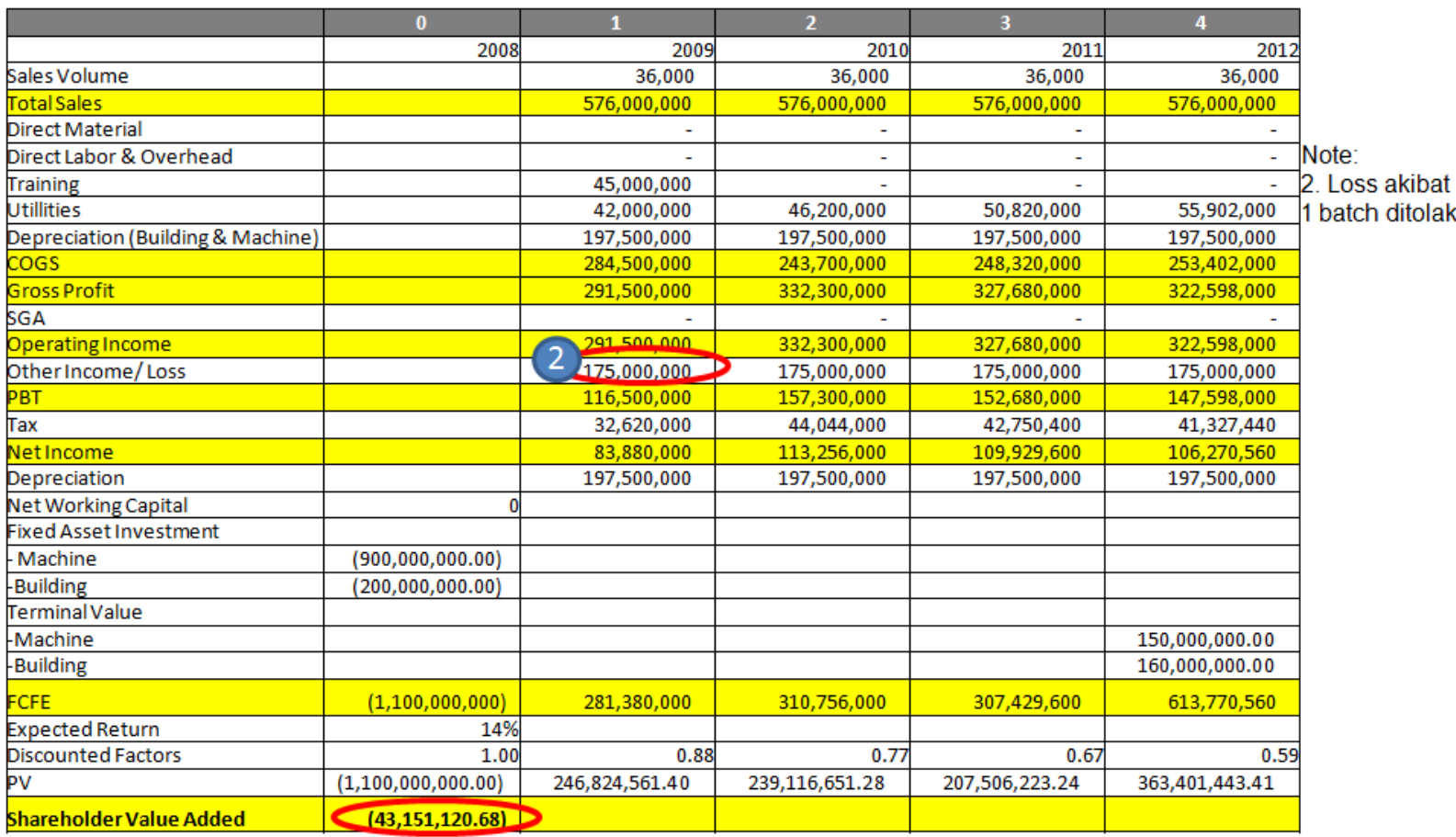

Tabel 12

Weighted NPV

\begin{tabular}{|l|c|c|c|c|}
\hline Scenario & Description & NPV & Weight & Weighted NPV \\
\hline Scenario 1 & no refused batch & $323,976,629.69$ & & $95.25 \% 308,587,739.78$ \\
\hline Scenario 2 & 1 batch refused & $(43,151,120.68)$ & \multicolumn{2}{|c|}{$4.75 \%(2,049,678.23)$} \\
\hline & & & Total Weighted NPV 306,538,061.55 \\
\hline
\end{tabular}

\section{PENUTUP}

Berdasarkan hasil analisis CVP dan NPV yang telah dilakukan, dapat diambil beberapa simpulan sebagai berikut: (1) harga yang ditawarkan oleh klien sebesar Rp14.000 tidak dapat diterima karena margin yang diberikan hanya sebesar 20.64\%, jauh dibawah profit yang diinginkan oleh perusahaan sebesar 27\%. Berdasarkan CVP, harga yang perlu diajukan adalah sebesar Rp16.000 dan nilai ini dapat diterima oleh klien setelah melalui proses negosiasi; (2) dengan harga yang baru sebesar Rp16.000, tawaran ini dapat disarankan untuk diterima perusahaan mengingat nilai weighted NPV sebesar Rp306 juta kepada perusahaan. Selain itu melalui perhitungan produktivitas, diterimanya tawaran ini dapat meningkatkan angka produktivitas perusahaan sebagaimana yang ditunjukkan dalam Tabel 13 berikut: 
Tabel 13

Produktivitas

\begin{tabular}{|l|r|r|}
\hline \multicolumn{1}{|c|}{ Parameter } & \multicolumn{1}{|c|}{ Before } & \multicolumn{1}{|c|}{ After } \\
\hline Manpower available & 95 & 95 \\
\hline Manhour per day & 760 & 760 \\
\hline Manhour used per day & 532 & 572 \\
\hline Utilization & $70 \%$ & $75.3 \%$ \\
\hline
\end{tabular}

\section{DAFTAR PUSTAKA}

Berk, Jonathan \& DeMarzo, Peter. (2007). Corporate Finance. Boston: Pearson Education. 